\title{
Research on the Structure Optimization of College Specialty under the Background of Economic Transition
}

\author{
Lihua Gong \\ Teaching Affaires Office of Taishan University Shandong Taian 27100, China
}

Keywords: Economic transition, College specialty, Structure optimization.

\begin{abstract}
Structure optimization of college specialty is adapted to the change of economic transition and upgrade. This paper made the corresponding elaboration with the relevance between economic transition and structure layout of college specialty as well as the principle of structure optimization of college specialty, and it also put forward the advice and countermeasures for structure optimization of college specialty.
\end{abstract}

\section{Introduction}

Nowadays, Chinese economic has entered the development stage of "new normal", and its core connotation is to realize the radical change of economic development from rapid rate, high efficiency and low cost to the sustainable innovation-driven direction. Meanwhile, college education is the significant carrier to train high-quality talents of economic development, and structure optimization of speciality is of great significance to support the economic transition.

\section{The relevance between Economic Transition and Structure Optimization of College Specialty}

\subsection{The Dynamic Mechanism of Regional Economic Development of College Service.}

College education, as one kind of modern educational model, has three characteristics, namely, college education, vocational education and regional education. Regional education, as one of the basic properties of colleges and universities, means the place where local colleges and service exist and makes the corresponding reflection with its value orientation. So the principle target of making the regional economic social development service as the start point and objective is to train the highquality talents for the local economic development. As for the colleges and universities, the orientation is its vital mission and the significant choice to enhance the talents quality and realize the sustainable development strategy. The ability of serving the local economic development is not only the symbol of talents training quality in regional colleges, but also the symbol of college quality.

\subsection{Economic Transition Has Put forward New Requirements for the College Specialty Structure Optimization.}

And seen from the surface, the competition among different countries is competing the the modern technology, product quality and service level, while its essence is the talents and education competition, especially the competition of technology-applied talents and corresponding education. Nowadays, our economic society is in the kew phrase of industrial adjustment and transition, and industrialization and information have acquired increasing development, which has an increasing demand with high-quality technological talents that are expected to support the labor force. In the rapid development of science and technology, industrial technology has accelerated its upgrade, so lots of new posts and the job requirements have made the corresponding changes. Meantime, along with the transition of industrial development and the constant separation of working posts in the technological level under the drive of science and technology and market, which leads to the uplifting of post technology and enhancing of post technology component. In addition, its labor content has a rather big degree enrichment and the technology of worker is required to uplift further. Under such development background, it is bound to play the decisive role whether the talents specialty structure can adapt to the inner demand of economic structure strategic transition. As for the current college 
education, the talents structure demand changes driven by the science and technology and market have put forward new requirements and challenges.

\subsection{College Education Has Entered a Rather Stable and Competitive Stage.}

Making certain strengthening with content construction and enhancing talents training quality are of great benefit to the participation in market competition. To occupy a significant place in the market competition, it must be based on the region, industrial docking and serving regional development. In the college talents training, the specialty is its basic unit and the connected point of college education and social demand. Specialty structure optimization is the most significant top design in the college development. As for the colleges, regional social economic development and industrial feature are the basic points of the specialty setting. To promote the vitality and professional value, college education must keep tight docking and adapt to the regional industrial characteristics and development demand, making the adjustment with specialty training objectives in the first place to achieve the tight docking of talents training and real production.

\section{Specialty Structure Characteristics and Optimization Principles of College Education}

College education plays a very significant role in our education system, and it is the vital component, with the principal objective of training high-quality and comprehensive talents based on the center of economic construction. At the same time, the specialty structure also has its own characteristics, mainly including the high technology, vocation, region and interactive subjects. The target of college talents training is to train the high-quality and advanced technology-applied professionals. As for the colleges, they should strictly obey the principle of "regarding the market demand as the center, the demand as the orientation, the ability as the standard and quality education as the main line" when launching the specialty structure optimization.

Firstly, regarding the economic development and market demand as the orientation. In the process of college specialty structure optimization, the economic and social development should be seen as the basis and the real demand of technology industry and posts should be regarded as the foundation. Meanwhile, the relationship between the variety of social demand and stability of teaching work should be settled effectively.

Secondly, specialty structure optimization should guarantee the scientific and systematic characteristic. Speaking essentially, the content of college specialty structure optimization is to require the scientific and standard specialty. When making the professional classifications, they should adapt to the relevant standards of professional classifications of the Ministry of Education, and the name should have certain standardization, also with the clear content, scientific extension and rational course structure group. Besides, when they are realizing the social demand and function, they are supposed to consider the economic rationality and optimized benefit. Before the specialty setup, they should do lots of survey and research and scientific certification, make the overall analysis with the soft conditions and hard conditions of the college and take full consideration of the optimization with college education resource of specialty setup so as to give full play to education resources and gain the greatest benefit from them.

Thirdly, making the effective strengthening with the practical part and launching the comprehensive cooperation between colleges and enterprises. Currently, Chinese college education reform direction is the cooperation of colleges and enterprises and industries and schools, which also is the significant requirement of social economic development for the college education. Taking the strength complementation and mutual benefit principle as the vital foundation and reference, and the technology and management members of the relevant enterprises should make the effective optimization with college specialty structure. Colleges should effectively solicit the suggestions on enterprises when making the specialty setup to effectively combine the short cycle of the market and long term of talents training and meet the current demand of enterprises and their long-term development.

Fourthly, regarding the working post as the important basis and training high-quality and hightechnology talents as the vital objective. Nowadays, the industrial development driven by the technology must make the overall training with high-quality and high-technology talents, highlight 
the enhancement of training practical abilities and strengthen the construction of colleges and related practical basis to achieve the cooperation between colleges ad enterprises and strengthen the comprehensive qualities and abilities of students.

\section{Countermeasures of the Structure Optimization of College Specialty}

4.1 Keep Close to the Market Demand and Actively Implement the Specialty Dynamic Upgrade. From the perspective of current industrial structure demand and college talents supply level, college specialty structure setting should firstly develop the professional of facilities manufacture, electronic information and ecological energy conservation in the later period. Colleges should regard training high-technology and applied talents as the main target, highlight the demand orientation and optimize the specialty course. Many colleges should keep close to the market demand and actively implement the specialty dynamic upgrade.

\subsection{Strictly Obey the Principle of Comparative Advantage and Pull the Construction and Development of Specialty Proup by the Characteristic Specialty.}

The popularity of a college mainly relies on its characteristic, and the most important is the difference with the characteristic specialty of other colleges. Colleges should strictly obey the principle of comparative advantage and take the own basis and condition as the significant foundation, make integrate the human and material resources of colleges and implement the key breakthrough to make the principal construction with characteristic specialty. Besides, they should truly serve the economy of enterprise and region that cannot be realized by the single characteristic specialty. Only the integration of a group of specialty surrounded with this industry can meet the demand of industrial development from various angles to truly realize it. Different colleges can make the effective construction with characteristic specialty and pull the paired specialty and the development of whole group. In general, colleges should make full use of the advantage platform and make their own advantages as the important basis and effectively refer to the advanced experiences of same specialty construction abroad based on the industrial structure, so as to enhance the quality and benefit of talents training to a great extent and make them more competitive in the talents competition as well as provide superior service for the local economic development.

\subsection{Deeply Launch the Practical Teaching and Comprehensively Enhance the inner Quality of \\ Specialty.}

The most prominent features of colleges include the perfect training conditions and practical teaching parts. However, various colleges have certain differences on the teaching. In general, compared with other differences, the difference on practical teaching is more significant. Colleges keep close to the related enterprises and they have the cooperation relationship, integrating the enterprise facilities and demand to achieve the overall cooperation between the both sides to launch progressive practical teaching with multi-levels and enhance the inner quality of specialty. As for the launching of practical teaching, the main part is to effectively launch the industrial alternation and experimental teaching, and their laughing is closely with the construction of college and practice basis. Making the corresponding construction with practice basis can give full play to colleges' resources to launch the construction and the common construction method of same enterprise.

\subsection{Give Full Play to the Regional Industrial Advantages and Strengthen the Professional Staff Construction.}

Due to the historical reasons, the entire quality of college teachers are rather low and their research abilities are inferior. Colleges should positively launch the combination with enterprises and construct a professional teaching staff. Firstly, give full play to the teachers training to communicate with enterprise and understand and master the development dynamic and demand of industry and enterprise in the first place so as to comprehensively train the quality and ability of professional teachers. Then colleges should spontaneously introduce the advance technical talents working with abundant experiences at the first line in the enterprise to shoulder the lecturers of colleges to comprehensively construct the dynamic enterprise part-time teaching staff. 


\subsection{Positively Launch the Cooperation between Colleges and Enterprises and Implement the Order Training of College Talents.}

Colleges must regard the regional economic development demand as its starting point and make full use of the natural geographical advantage same with lots of enterprises and the demand of enterprises for talents as the center to adjust the specialty setup and teaching method in the first place and apply various cooperation model. Firstly, colleges and the related cooperated enterprises establish the talents training basis and introduce the enterprise environment and resource to achieve the perfect docking between colleges and enterprises. Colleges can train students for enterprises and enterprises can offer the condition for students' practice to realize the win-win. Secondly, colleges and cooperated enterprises implement the order training and industry and school alternation training, and both sides commonly regulate the talents training plan to combine the work with study and realize the tripartite win-win of colleges, enterprises and students.

\section{The Suggestions with the Structure Optimization of College Specialty}

\subsection{Colleges can Make Full Use of the Geographical Advantages.}

College specialty construction should be based on its own conditions and make full use of the surrounding resource advantages that can be applied so as to launch the integration construction of college specialty in the whole and realize the construction resources sharing among different schools. Furthermore, it can manifest the own characteristic of specialty construction in different schools and realize the complementation of different colleges to enhance its effect in general and satisfy with the industrial demand.

\subsection{The Government should Give Full Play to Its Link Function and Make the Comprehensive Construction with the Information Communication Platform between Colleges and Enterprises.}

The government links the colleges and enterprises and provides the information needed by the both sides to realize the effective communication. Firstly, the government can make the effective construction with the daily timely communication platform in the process of constructing the net communication platform between colleges and enterprises. And enterprise staff and college teachers can respectively publish their learning technological projects to launch the good communication. Secondly, the government can routinely launch the salon of colleges and enterprises to construct the physical platform where colleges and enterprises can communicate with each other face to face to strengthen the understanding.

\section{Conclusion}

Nowadays, lots of local social economic development is in the key phrase of transition and upgrade, and the prominent characteristic college education should prove high-quality and high-technology talents for the local economic development and make the continual optimization and adjustment with specialty structure. Therefore, from the angle of colleges, the talents demand characteristic under the background of industrial transition and upgrade must be taken as the significant basis. And they should effectively construct the mechanism of actively implementing the professional dynamic adjustment and upgrade, constantly reform and innovate the professional training model of colleges and launch the optimization of specialty structure to train more high-quality and high-technology talents

\section{References}

[1] Hui Shen, Kerong Zhang. Research on the Optimization Mechanism of Local College Specialty with Industry Structure Adjustment[J]. Journal of Ningbo University(Education and Science), 2017,39(05):48-51.

[2]Jiao Wang. The Influence of Economic Structure Adjustment on the Local College Specialty Setting in Jilin Province[J/OL]. Modern Communication[2017-12-25]. 
[3]Zhiqiang Lv. The Analysis of Structure Optimization and Adjustment in Colleges and Universities[J].Science and Technology Innovation Herald,2017,14(13):215-216+218.

[4] Runtong Wang,Shu Yu. Research on the Transformed College Specialty Structure Optimization in the Horizon of Supply-side Reform[J].Education Science \& Culture Magazine(The latter month),2016(09):131-132.

[5] Changqing Xu. Research on the College Specialty Setting Optimization in Guangdong Province Based on the Regional Industry Structure Adjustment[J].Modern Education Science, 2014(03): 154-156.

[6] Yi Shi. Interactive Development Analysis of College Specialty Structure Optimization and Regional Economy - Taking the A Institute of Shanxi Province as the Example[J]. New West (theory), 2014(01):12-13.

[7]Da Wang. Research on the Local College Specialty Setting and Structure Optimization in Heilongjiang Province — Taking the Heilongjiang Institute of Technology as the Example [J]. China Science and Technology Information ,2012(12):220.

[8] Xiuqin Xia. Research on the Relationship of Regional Industrial Structure Adjustment and College Specialty Structure Optimization - Taking the Huzhou Teachers College as the Example[J]. Exam Weekly,2011(57):190-192. 